\title{
Risk Factors and Clinical Significance of D-Dimer in the Development of Postoperative Venous Thrombosis in Patients with Lung Tumor
}

This article was published in the following Dove Press journal: Cancer Management and Research

\author{
Pan Wang ${ }^{1} *$ \\ Honglin Zhaol,* \\ Qingchun Zhao',* \\ Fan Ren (D) \\ Ruifeng Shi' \\ Xingyu Liu' \\ Jinghao Liu (D) \\ Hongyu Liu ${ }^{2}$ \\ Gang Chen' \\ Jun Chen $\left(\mathbb{D}^{1,2}\right.$ \\ 'Department of Lung Cancer Surgery, \\ Tianjin Medical University General \\ Hospital, Tianjin, People's Republic of \\ China; ${ }^{2}$ Tianjin Key Laboratory of Lung \\ Cancer Metastasis and Tumor \\ Microenvironment, Tianjin Lung Cancer \\ Institute, Tianjin Medical University \\ General Hospital, Tianjin, People's \\ Republic of China \\ *These authors contributed equally to \\ this work
}

Background: The incidence of venous thromboembolism (VTE) is higher in patients with lung cancer. The aim of this study was to investigate the risk factors associated with postoperative VTE and explore the VTE predication capacity of D-dimer kinetics.

Patients and Methods: Six hundred patients who had lung tumor surgery were analyzed retrospectively between January 2018 and August 2019, and venous ultrasound imaging and D-dimer examination before and after surgery were recommended to all operative patients. Of these 600 patients, 523 patients had venous thromboembolism after surgery, and 77 patients had not found. The general clinical data, postoperative prophylactic anticoagulant therapy, early systemic thromboprophylaxis, $50 \%$ increment of D-dimer, $100 \%$ increment of D-dimer, and perioperative (preoperative and days 1, 3, and 5 after surgery) D-dimer levels were collected. Logistic regression analysis was used to analyze the independent risk factors of postoperative VTE.

Results: VTE developed in $77(12.8 \%)$ patients. In a univariate analysis, age, surgical approach, tumor size, histology, postoperative preventive anticoagulation, postoperative limb compression therapy, postoperative hemostasis, duration of operation, early systemic thromboprophylaxis, $100 \%$ increment of D-dimer, preoperative and postoperative D-dimer level, intraoperative blood loss, and time spent in the hospital were significantly different between the thrombus group and nonthrombus group $(P<0.05)$. Multivariate analysis showed that age $>60$ years $(P=0.006)$ and D-dimer level on 5 days after surgery $(P=$ $0.000)$ were significant independent risk factors for VTE. Postoperative D-dimer was significantly higher than the preoperative level $(P<0.001)$. Postoperative D-dimer level was significantly different between benign and malignant tumor groups $(P<0.05)$ and between the thrombus group and nonthrombus group $(P<0.001)$. Preventive anticoagulation and limb compression therapy starting from the first day after surgery was statistically significant between the thrombus group and the nonthrombus group $(P<0.05)$.

Conclusion: Continuous detection of D-dimer level after pulmonary tumor surgery combined with thrombotic-related risk factors can better evaluate the occurrence of VTE. Preventive anticoagulant therapy and limb compression therapy starting from the first day after surgery can effectively reduce the incidence of VTE.

Keywords: anticoagulants, D-dimer, lung neoplasms, risk factors venous thromboembolism

\section{Introduction}

Venous thromboembolism (VTE) mainly includes deep vein thrombosis (DVT) and pulmonary embolism (PE). Twenty percent of VTE deaths are associated with cancer, and patients with cancer and VTE have 3 times the risk of death as those
Correspondence: Jun Chen

Email huntercj2004@yahoo.com 
without VTE. ${ }^{1,2}$ The incidence of VTE in lung cancer is $7 \%$ to $13 \%$, which is the highest incidence of VTE in malignant tumors. ${ }^{3-5}$ In addition, surgery and chemotherapy can directly increase the risk of VTE. ${ }^{6,7}$ Plasma Ddimer is a hydrolytic product of fibrin monomers. Elevated D-dimer level often indicates hypercoagulability and secondary fibrinolysis hyperactivity in the blood. Therefore, D-dimer level can be used as an additional test for VTE. However, the blood of patients with lung cancer is often in a hypercoagulable state and activates a partial coagulation cascade, which results in a naturally high D-dimer level; ${ }^{8}$ therefore, defining the D-dimer threshold as $500 \mathrm{ng} / \mathrm{mL}$ may not accurately assess the risk of VTE. In addition, domestic and foreign guidelines for VTE suggest that anticoagulant therapy such as low-molecular-weight heparin (LMWH) should be recommended for patients with diagnosed or suspected tumors without anticoagulant contraindications. ${ }^{9,10}$ Nevertheless, there was no consistent conclusion on the type, dose, and starting time of preventive anticoagulant therapy for patients after surgery to excise lung tumors. Hence, this study aimed to explore the changes in D-dimer level in patients undergoing lung surgery and how to manage preventive anticoagulant therapy after lung tumor surgery.

\section{Patients and Methods Clinical Data}

This study retrospectively analyzed the data of 675 patients who had lung tumor surgery during the period from January 2018 to August 2019 at the Department of Lung Cancer Surgery, Tianjin Medical University General Hospital. Patients without a history of venous thrombosis, chemotherapy, and radiotherapy were included in the study. Patients with the following history were excluded from the study: (1) anticoagulant drugs within 1 month before entering the hospital; (2) blood transfusion; (3) surgery or trauma within 3 months of admission; or (4) VTE. Seventy-five patients were excluded because they did not meet the inclusion criteria. Finally, 600 eligible patients were included (Figure 1). There were 135 cases of benign tumor, including 48 cases of inflammatory pseudotumor $(35.6 \%), 25$ cases of tuberculoma (18.5\%), 10 cases of hamartoma (7.4\%), and 52 cases of other benign tumors $(38.5 \%)$. There were 465 patients with malignant tumor, including $314(67.5 \%)$ with adenocarcinoma, 98 (21.1\%) with squamous cell carcinoma, $15(3.2 \%)$ with small cell carcinoma, 7 (1.5\%) with large cell carcinoma, and $31(6.7 \%)$ with other malignant tumors. Table 1 shows the patient's clinical data. The collected information included sex, age, smoking history, hypertension history, diabetes history, surgical approach, duration of operation, intraoperative blood loss, time spent in the hospital, histology, tumor size, pathological stages, postoperative preventive anticoagulation (as-needed subcutaneous injections of nadroparin calcium starting the first day after surgery), postoperative limb compression therapy (venous thrombosis prevention device for double lower limb compression massage for 15 minutes from the first day after surgery, 2 times a day), postoperative hemostasis, early systemic thromboprophylaxis (prophylactic anticoagulation and limb compression therapy began on the first day after surgery), 50\% and 100\% increment of D-dimer (the D-dimer level on the first day after surgery increased by $50 \%$ and $100 \%$ compared with the preoperative period), and D-dimer levels measured preoperatively and on days 1,3 , and 5 after surgery.

\section{Diagnosis of VTE}

Venous ultrasound imaging was used to confirm DVT events and was recommended for all operative patients. PE events were confirmed by computed tomography pulmonary angiogram. This study was conducted in accordance with the Declaration of Helsinki. The study protocol was reviewed and approved by the institutional review boards of the participating institutions.

\section{Statistical Analysis}

Statistical analyses were conducted with SPSS version 22.0. Continuous variables were presented as mean and standard deviation or median and percentile 25 (p25) and percentile 75 (p75), and categorical variables as absolute and relative percentages. Categorical variables were analyzed with the chi-squared test. Continuous variables were compared using the $t$ test, the nonparametric MannWhitney $U$-test, or the Friedman test. The Bonferroni method was used to correct for multiple comparisons. The independent risk factors of postoperative VTE were analyzed by binary logistic regression. The level of statistical significance was set at $P<0.05$.

\section{Results}

\section{Clinical Features and Risk Factors of VTE}

Among the 600 patients, 77 patients had lower extremity venous thrombosis, including 73 patients (12.3\%) with lower extremity muscular calf vein thrombosis (MCVT) and 4 patients $(0.6 \%)$ with proximal DVT. There were not 


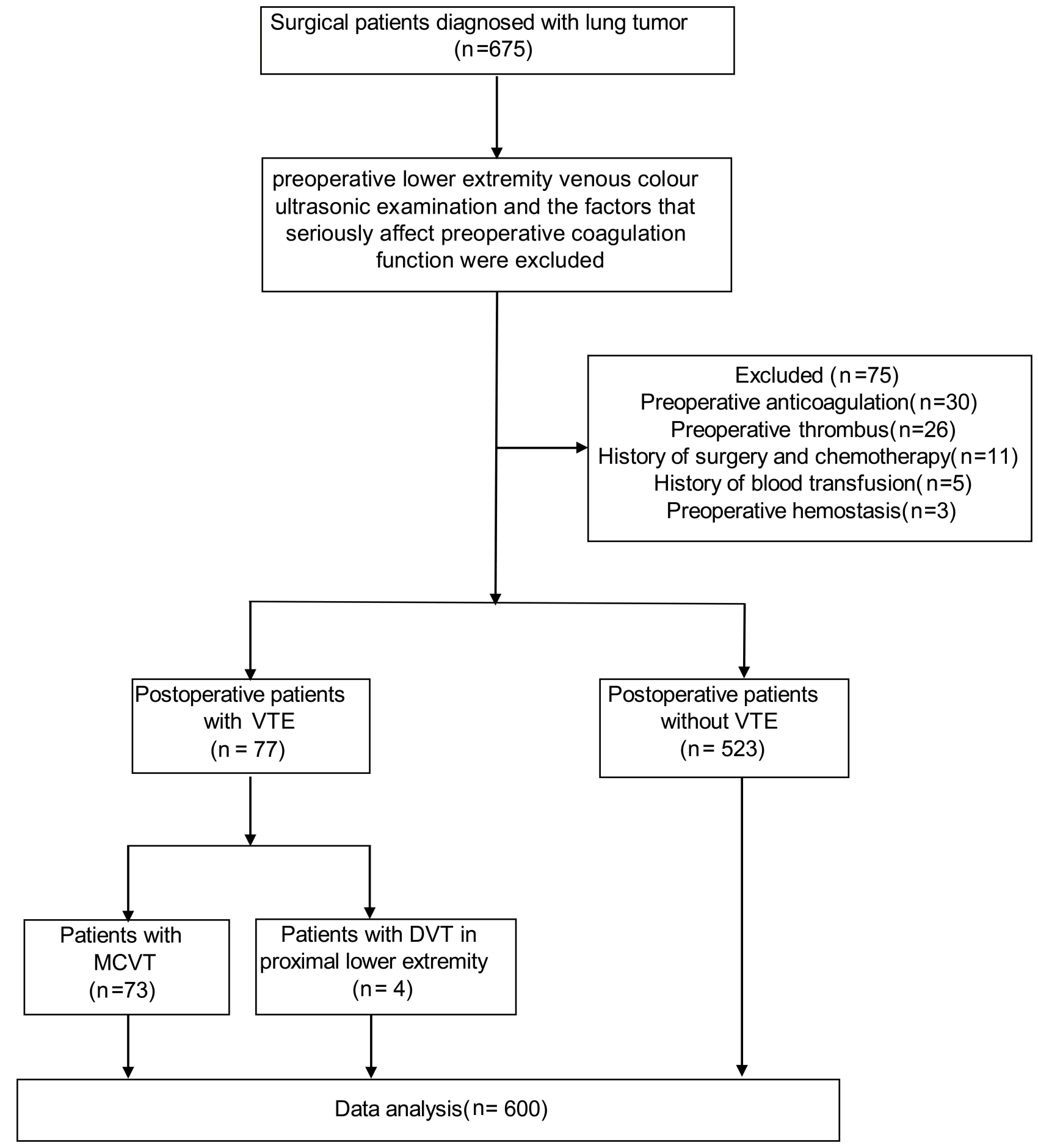

Figure I Study flow diagram. VTE, venous thromboembolism; MCVT, muscular calf vein thrombosis; DVT, deep venous thrombosis.

any death cases due to venous thrombosis of the lower extremities or PE.

Tables 2 and 3 showed that sex, smoking history, hypertension, diabetes mellitus, $50 \%$ increment of Ddimer, and pathological stages have no significant difference $(P>0.05)$, but the age, surgical approach, tumor size, histology, postoperative anticoagulation, limb compression therapy, postoperative hemostasis, duration of operation, preoperative and days 1, 3, and 5 D-dimer level after surgery, intraoperative blood loss, early systemic thromboprophylaxis, $100 \%$ increment of D-dimer, and time spent in the hospital between the thrombus group and 
Table I Clinical Characteristics of Patients

\begin{tabular}{|c|c|}
\hline Category & n (\%) \\
\hline \multicolumn{2}{|l|}{ Age (y) } \\
\hline$\leq 60$ & $237(39.5)$ \\
\hline$>60$ & $363(60.5)$ \\
\hline \multicolumn{2}{|l|}{ Sex } \\
\hline Male & $339(56.5)$ \\
\hline Female & $26 I(43.5)$ \\
\hline \multicolumn{2}{|l|}{ Smoking history } \\
\hline Ever & $258(43.0)$ \\
\hline Never & $342(57.0)$ \\
\hline \multicolumn{2}{|l|}{ Hypertension history } \\
\hline Yes & $210(35.0)$ \\
\hline No & $390(65.0)$ \\
\hline \multicolumn{2}{|l|}{ Diabetes history } \\
\hline Yes & $77(12.8)$ \\
\hline No & $523(87.2)$ \\
\hline \multicolumn{2}{|l|}{ Surgical approach } \\
\hline Thoracoscopy & $435(72.5)$ \\
\hline Thoracotomy & $165(27.5)$ \\
\hline \multicolumn{2}{|l|}{ Tumor size $(\mathrm{cm})$} \\
\hline$<3$ & $379(63.2)$ \\
\hline$\geq 3$ & $221(36.8)$ \\
\hline \multicolumn{2}{|l|}{ Histology } \\
\hline Benign tumor & $135(22.5)$ \\
\hline Malignant tumor & $465(77.5)$ \\
\hline \multicolumn{2}{|l|}{ Postoperative anticoagulation } \\
\hline Yes & $220(36.7)$ \\
\hline No & $380(63.3)$ \\
\hline \multicolumn{2}{|l|}{ Limb compression therapy } \\
\hline Yes & $489(81.5)$ \\
\hline No & $\mathrm{III}(18.5)$ \\
\hline \multicolumn{2}{|l|}{ Postoperative hemostasis } \\
\hline Yes & $91(15.2)$ \\
\hline No & $509(84.8)$ \\
\hline \multicolumn{2}{|l|}{ Duration of operation $(\mathrm{h})$} \\
\hline$<3$ & $342(57.0)$ \\
\hline$\geq 3$ & $258(43.0)$ \\
\hline \multicolumn{2}{|l|}{ Pathological stages } \\
\hline$I+I I$ & $320(69.6)$ \\
\hline III+IV & $140(30.4)$ \\
\hline \multicolumn{2}{|l|}{ VTE } \\
\hline Yes & $77(12.8)$ \\
\hline No & $523(87.2)$ \\
\hline
\end{tabular}

Abbreviation: VTE, venous thromboembolism. nonthrombus group have a significant difference $(P<0.05)$. In order to eliminate the confounding factors, the risk factors with statistical significance in a singlefactor analysis were analyzed by binary logistic regression analysis and the results showed that age and D-dimer on day 5 after surgery were independent risk factors for postoperative lower extremity venous thrombosis $(P<0.05)$ (Table 4). The incidence of lower extremity venous thrombosis at age $\leq 60$ years was 0.388 times that at age $>60$ years (odds ratio $[\mathrm{OR}]=0.388 ; P=0.006$ ), and the risk of venous thrombosis in the lower extremity was doubled for every increased $1 \mathrm{ng} / \mathrm{mL}$ of D-dimer number on day 5 after surgery $(\mathrm{OR}=1.001 ; P=0.000)$.

\section{Characteristics of D-Dimer During the Perioperative Period}

The level of D-dimer after surgery was significantly higher than that before surgery, and it was significantly different not only in the benign tumor group but also in the malignant tumor group $(P<0.001)$ (Figure 2$)$. The median preoperative $\mathrm{D}$-dimer level was $240 \mathrm{ng} / \mathrm{mL}$ in the benign tumor group and $387 \mathrm{ng} / \mathrm{mL}$ in the malignant tumor group, and there was no statistical difference between the 2 groups $(P=0.097)$. However, the difference in postoperative D-dimer level between the benign and malignant group was statistically significant $(P<0.05)$ (Figure 3 ). The comparison of D-dimer level between the preoperative and postoperative different time points was statistically significant not only in the thrombus group but also in the nonthrombus group $(P<0.001)$, and the difference in D-dimer level between the thrombus group and the nonthrombus group was also statistically significant (Figure 4).

\section{Prophylactic Management of VTE}

In the analysis of prophylactic treatment of VTE, subcutaneous injection with different doses of nadroparin calcium was started at different times. It was found that the preventive anticoagulant injection started on the first day after the operation showed a significant difference between the thrombus group and the nonthrombus group $(P<0.05)$. However, when nadroparin calcium was given as preventive anticoagulant therapy on the second day after the operation, no statistical significance was found between the thrombus group and the nonthrombus 
Table 2 Univariate Analysis of Categorical Data of Lower Extremity Venous Thrombosis in Postoperative Patients

\begin{tabular}{|c|c|c|c|c|c|}
\hline Risk Factors & & $\operatorname{VTE}(+)(n=77)$ & $\operatorname{VTE}(-)(n=523)$ & $\chi^{2}$ & $\mathbf{P}$ \\
\hline Gender & $\begin{array}{l}\text { Male(\%) } \\
\text { Female(\%) }\end{array}$ & $\begin{array}{l}39(11.5) \\
38(14.6)\end{array}$ & $\begin{array}{l}300(88.5) \\
223(85.4)\end{array}$ & 1.230 & 0.267 \\
\hline Age(yr) & $\begin{array}{l}\leq 60(\%) \\
>60(\%)\end{array}$ & $\begin{array}{l}15(6.3) \\
62(17.1)\end{array}$ & $\begin{array}{l}222(93.7) \\
301(82.9)\end{array}$ & 14.815 & $0.000 *$ \\
\hline Smoking history & $\begin{array}{l}\text { No(\%) } \\
\text { Yes(\%) }\end{array}$ & $\begin{array}{l}47(13.7) \\
30(11.6)\end{array}$ & $\begin{array}{l}295(86.3) \\
228(88.4)\end{array}$ & 0.588 & 0.443 \\
\hline Hypertension history & $\begin{array}{l}\text { No(\%) } \\
\text { Yes(\%) }\end{array}$ & $\begin{array}{l}43(11.0) \\
34(16.2)\end{array}$ & $\begin{array}{l}347(89.0) \\
176(83.8)\end{array}$ & 3.255 & $0.07 I$ \\
\hline Diabetes history & $\begin{array}{l}\text { No(\%) } \\
\text { Yes(\%) }\end{array}$ & $\begin{array}{l}65(12.4) \\
12(15.6)\end{array}$ & $\begin{array}{l}458(87.6) \\
65(84.4)\end{array}$ & 0.598 & 0.439 \\
\hline Surgical approach & $\begin{array}{l}\text { Thoracoscopy(\%) } \\
\text { Thoracotomy(\%) }\end{array}$ & $\begin{array}{l}43(9.9) \\
34(20.6)\end{array}$ & $\begin{array}{l}392(90.1) \\
|3|(79.4)\end{array}$ & $12.29 \mid$ & $0.000 *$ \\
\hline Tumor size & $\begin{array}{l}<3 \mathrm{~cm}(\%) \\
\geq 3 \mathrm{~cm}(\%)\end{array}$ & $\begin{array}{l}38(10.0) \\
39(17.6)\end{array}$ & $\begin{array}{l}34 \mid(90.0) \\
\mid 82(82.4)\end{array}$ & 7.247 & $0.007^{*}$ \\
\hline Histology & $\begin{array}{l}\text { Benign tumor(\%) } \\
\text { Malignant tumor(\%) }\end{array}$ & $\begin{array}{l}10(7.4) \\
67(14.4)\end{array}$ & $\begin{array}{l}125(92.6) \\
398(85.6)\end{array}$ & 4.584 & $0.032 *$ \\
\hline Postoperative anticoagulation ${ }^{\mathrm{a}}$ & $\begin{array}{l}\text { No(\%) } \\
\text { Yes(\%) }\end{array}$ & $\begin{array}{l}58(15.3) \\
19(8.6)\end{array}$ & $\begin{array}{l}322(84.7) \\
201(91.4)\end{array}$ & 5.470 & $0.019 *$ \\
\hline Limb compression therapy & $\begin{array}{l}\text { No(\%) } \\
\text { Yes(\%) }\end{array}$ & $\begin{array}{l}23(20.7) \\
54(I 1.0)\end{array}$ & $\begin{array}{l}88(79.3) \\
435(89.0)\end{array}$ & 7.574 & $0.006 *$ \\
\hline Postoperative hemostasis & $\begin{array}{l}\text { No(\%) } \\
\text { Yes(\%) }\end{array}$ & $\begin{array}{l}56(11.0) \\
21(23.1)\end{array}$ & $\begin{array}{l}453(89.0) \\
70(76.9)\end{array}$ & 10.062 & $0.002 *$ \\
\hline Duration of operation & $\begin{array}{l}<3 \mathrm{~h}(\%) \\
\geq 3 \mathrm{~h}(\%)\end{array}$ & $\begin{array}{l}32(9.4) \\
45(17.4)\end{array}$ & $\begin{array}{l}310(90.6) \\
213(82.6)\end{array}$ & 8.594 & $0.003 *$ \\
\hline Pathological stages & $\begin{array}{l}\text { I+II(\%) } \\
\text { III+IV(\%) }\end{array}$ & $\begin{array}{l}47(14.7) \\
18(12.9)\end{array}$ & $\begin{array}{l}273(85.3) \\
122(87.1)\end{array}$ & 0.269 & 0.604 \\
\hline Early systemic thromboprophylaxis ${ }^{b}$ & $\begin{array}{l}\text { No(\%) } \\
\text { Yes(\%) }\end{array}$ & $\begin{array}{l}61(14.8) \\
16(8.6)\end{array}$ & $\begin{array}{l}352(85.2) \\
|7|(9 \mid .4)\end{array}$ & 4.443 & $0.035 *$ \\
\hline $50 \%$ increment of D-dimer ${ }^{c}$ & $\begin{array}{l}\text { No(\%) } \\
\text { Yes(\%) }\end{array}$ & $\begin{array}{l}20(11.9) \\
57(13.2)\end{array}$ & $\begin{array}{l}148(88.1) \\
375(86.8)\end{array}$ & 0.180 & 0.671 \\
\hline $100 \%$ increment of D-dimer ${ }^{d}$ & $\begin{array}{l}\text { No(\%) } \\
\text { Yes(\%) }\end{array}$ & $\begin{array}{l}27(9.3) \\
50(16.1)\end{array}$ & $\begin{array}{l}262(90.7) \\
261(83.9)\end{array}$ & 6.074 & $0.014 *$ \\
\hline
\end{tabular}

Notes: ${ }^{a}$ As-needed subcutaneous injections of nadroparin calcium starting the first day after surgery. ${ }^{\mathrm{b}}$ Prophylactic anticoagulation and limb compression combined therapy began on the first day after surgery. ${ }^{\mathrm{C}}$ The D-dimer level on the first day after surgery increased by $50 \%$ compared with the preoperative period. ${ }^{\mathrm{d}}$ The $\mathrm{D}$-dimer level on the first day after surgery increased by 100\% compared with the preoperative period. *Indicates statistical significance, $P<.05$.

Abbreviation: VTE, venous thromboembolism.

group, even if the patient was given regular $(0.4 \mathrm{~mL} /$ day $)$ subcutaneous injections or at a larger dose and frequency (Table 5). Besides, our study showed that there were significant differences between early systemic thromboprophylaxis and regular anticoagulation day 1 after surgery (Nadroparin calcium was injected regularly at least $0.4 \mathrm{~mL}$ daily.), limb compression therapy, and non-treatment in the comparison between thrombus group and nonthrombus group $(P=.037)$ (Supplemental Table 1).

\section{Discussion}

VTE is one of the leading causes of morbidity and mortality in patients with cancer. Approximately one-fifth of patients with VTE are diagnosed with malignant tumors 
Table 3 Univariate Analysis of Measurement Data of Lower Extremity Venous Thrombosis in Postoperative Patients

\begin{tabular}{|l|l|l|l|l|}
\hline Risk Factors & & VTE (+) & VTE (-) \\
\hline D-dimer (ng/mL) & Before surgery & $482(342,944)$ & $36 I(256,573)$ & P \\
& Day I after surgery & $1717(922,2675)$ & $77 I(539,1105)$ & $0.000 *$ \\
& Day 3 after surgery & $1649(1024,2544)$ & $680(485,1036)$ & $0.000 *$ \\
& Day 5 after surgery & $2293(1287,38 I I)$ & $946(684,1348)$ & $0.000 *$ \\
& & $50(30,100)$ & $50(20,50)$ & $0.000 *$ \\
\hline Blood loss $(\mathrm{mL})$ & & $16(15,23)$ & $15(13,19)$ & $0.00 I^{*}$ \\
Time in hospital (d) & & & \\
\hline
\end{tabular}

Note: *Indicates statistical significance, $P<.05$.

Abbreviation: VTE, venous thromboembolism.

Table 4 Two-Class Logistic Regression Analysis of Lower Extremity Venous Thrombosis in Postoperative Patients

\begin{tabular}{|c|c|c|c|c|c|c|c|}
\hline \multirow[t]{2}{*}{ Risk Factors } & \multirow[t]{2}{*}{ B } & \multirow[t]{2}{*}{ Standard Error } & \multirow[t]{2}{*}{ Wald } & \multirow[t]{2}{*}{$\mathbf{P}$} & \multirow[t]{2}{*}{ OR } & \multicolumn{2}{|l|}{$95 \% \mathrm{Cl}$} \\
\hline & & & & & & Lower & Upper \\
\hline Age & -0.948 & 0.346 & 7.511 & $0.006 *$ & 0.388 & 0.197 & 0.763 \\
\hline D-dimer level day 5 after surgery & 0.001 & 0 & 29.358 & $0.000 *$ & 1.001 & 1.001 & 1.001 \\
\hline
\end{tabular}

Note: *Indicates statistical significance, $P<.05$.

Abbreviations: $\mathrm{OR}$, odds ratio. $\mathrm{Cl}$, confidence interval.

simultaneously, ${ }^{1,10,11}$ and VTE is the most common cause of death after cancer surgery. ${ }^{12}$ Compared with other types of tumors, the risk of VTE in lung cancer is very high. If we consider the high incidence of lung cancer, lung cancer may be one of the cancers with the highest incidence of cancer-related thrombosis. ${ }^{13}$ The overall incidence of VTE after surgery in this study was $12.8 \%$, of which benign and malignant tumors were $7.4 \%$ and $14.4 \%$, respectively. This

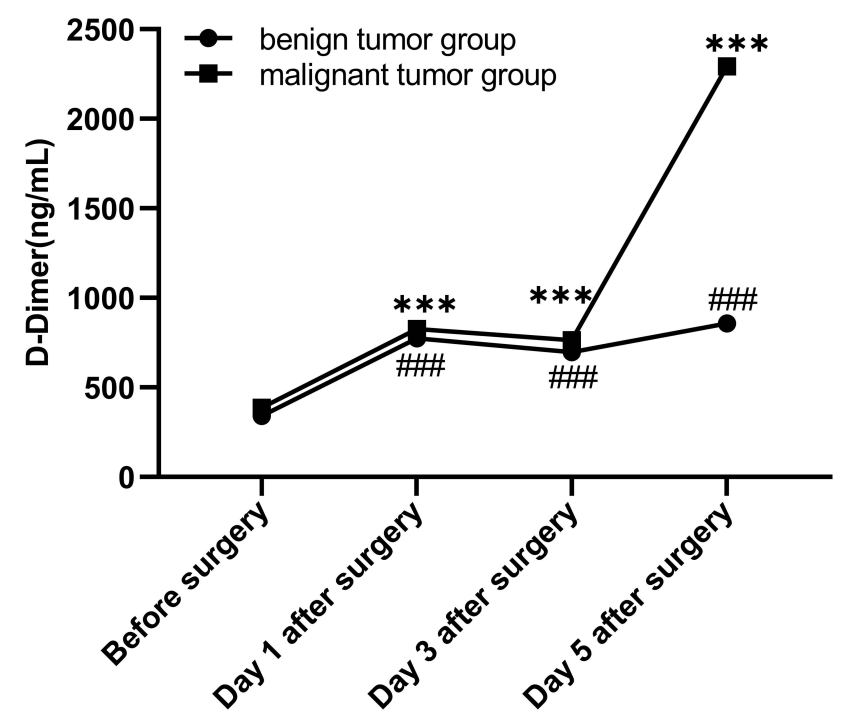

Figure 2 Comparison of D-dimer level at different time points in the benign tumor group and malignant tumor group. $* * * P<.00 \mathrm{I}$, the difference between preoperative and postoperative D-dimer levels is statistically significant in the benign tumor group. $P<.001$, the difference in D-dimer level is statistically significant in the malignant tumor group. is consistent with previous studies (Table 6) and it again shows that the incidence of postoperative VTE is higher than other tumors and highlights the importance of postoperative anticoagulation.

Prior studies show that platinum-containing chemotherapeutic drugs, ${ }^{26,27}$ interleukin 6 , tumor necrosis factor, ${ }^{28}$ antiangiogenic agents (bevacizumab), ${ }^{29}$ platelet count, ${ }^{30}$ age, tumor pathology type (adenocarcinoma) ${ }^{31}$ time spend

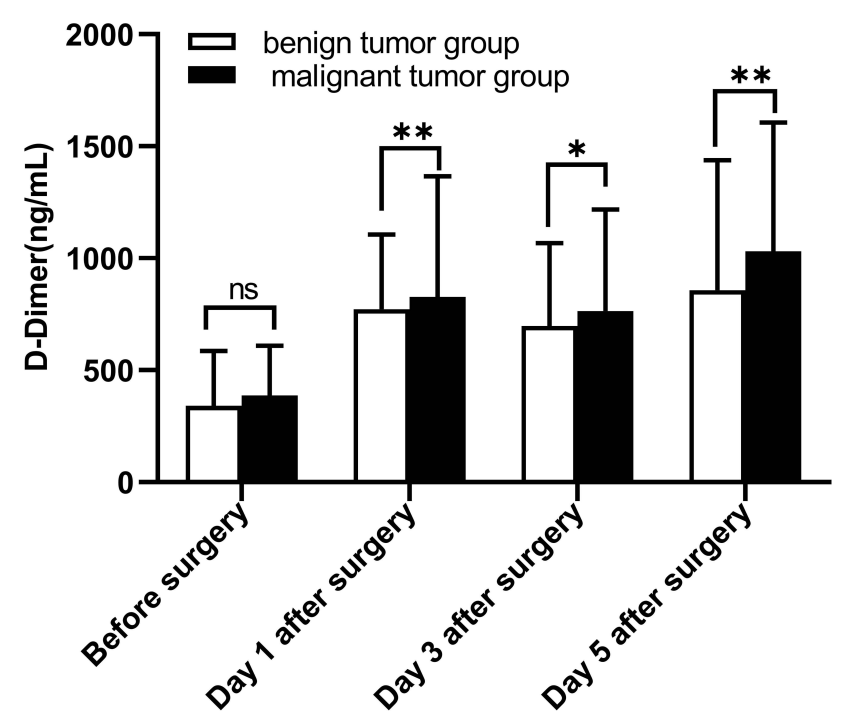

Figure 3 Comparison of D-dimer level at different time points between benign tumor group and malignant tumor group. NS, the difference was not statistically significant. *Indicates statistical significance, $P<.05$. **Indicates statistical significance, $P<.0$ I. 


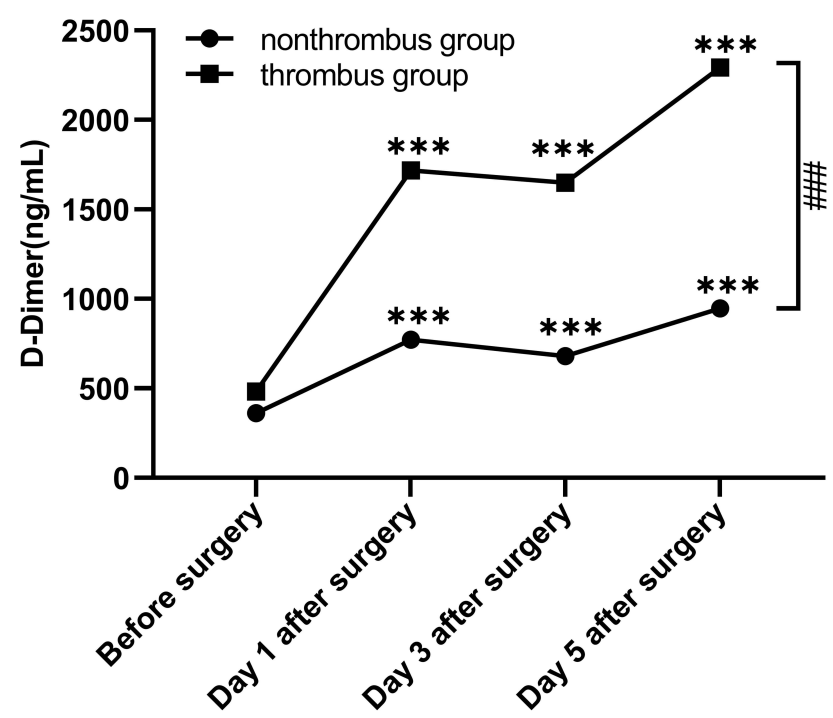

Figure 4 Comparison of D-dimer level at different time points in the thrombus group and nonthrombus group. $* * * P<.001$, the difference between preoperative and postoperative D-dimer levels is statistically significant in the thrombus group and nonthrombus group; ${ }^{\#} P<.00 \mathrm{I}$, the difference in $D$-dimer level is statistically significant between the thrombus group and nonthrombus group.

in the hospital, ${ }^{32}$ obesity, and surgery can increase the risk of VTE. ${ }^{33,34}$ Other studies show that the incidence of VTE is the highest within 1 month after operation, after which the risk is gradually reduced. ${ }^{35,36}$ The risk of venous thrombosis is $4.2 \%$ in patients undergoing lung cancer surgery before discharge, and $77 \%$ of patients with VTE are diagnosed before discharge. ${ }^{36,37}$ Nevertheless, there are few studies on the incidence of postoperative thrombus in patients undergoing lung tumor surgery, which is one of the advantages of this study. We found that the incidence of VTE in patients with thoracotomy, operation time $>3$ hours, more blood loss during surgery, and longer time spent in the hospital was higher than that in the control group. Moreover, age and
D-dimer on day 5 after surgery were independent risk factors for lower limb venous thrombosis. We found that the incidence of postoperative thrombus in patients with age $>60$ years $(17.1 \%)$ was significantly higher than that in patients with age $\leq 60$ years $(6.3 \%)$. Several studies also show that age is a risk factor for thrombosis. ${ }^{38,39}$ In addition, the Ddimer level on day 5 after surgery was significantly higher than the other time points, and the most significant difference was noted between the thrombus group and the nonthrombus group. Therefore, it is necessary to perform a timely check of coagulation function on day 5 after surgery.

D-dimer is positive for the prediction of thrombosis, but previous studies show that the current threshold does not properly assess the occurrence of thrombosis, and it is recommended to adjust the threshold to $3500 \mathrm{ng} / \mathrm{mL}$ or $2000 \mathrm{ng} / \mathrm{mL}^{40-42} \mathrm{D}$-dimer level increases first and then decreases in the first 10 days after surgery. ${ }^{40,42}$ We found that the median postoperative D-dimer level in the thrombus group, the nonthrombus group, the benign tumor group, and the malignant tumor group were all $>500 \mathrm{ng} / \mathrm{mL}$. Therefore, whether to define the critical level of D-dimer as $500 \mathrm{ng} / \mathrm{mL}$ after tumor surgery needs further consideration and research. In addition, when comparing the doubled D-dimer level on the first day after surgery with pre-surgery, the occurrence of venous thrombosis should be alerted because our data showed that the incidence of thrombosis was significantly increased. Postoperative plasma D-dimer was significantly different not only in the thrombus and nonthrombus groups but also in the benign and malignant tumor groups. Therefore, we suggest that regular review of D-dimer levels is necessary for postoperative patients, especially in the first week after surgery.

Table 5 Analysis of Postoperative Venous Thrombosis of Lower Extremity Under Different Anticoagulation Conditions

\begin{tabular}{|c|c|c|c|c|}
\hline Anticoagulant Condition & & VTE (+) & VTE (-) & $\boldsymbol{P}$ \\
\hline Anticoagulation day I after surgery ${ }^{a}$ & $\begin{array}{l}\text { Yes(\%) } \\
\text { No(\%) }\end{array}$ & $\begin{array}{l}19(8.6) \\
58(15.3)\end{array}$ & $\begin{array}{l}201(91.4) \\
322(84.7)\end{array}$ & $0.019 *$ \\
\hline Anticoagulation day I after surgery ${ }^{b}$ & $\begin{array}{l}\text { Yes(\%) } \\
\text { No(\%) }\end{array}$ & $\begin{array}{l}17(8.6) \\
60(14.9)\end{array}$ & $\begin{array}{l}181(91.4) \\
342(85.1)\end{array}$ & $0.029 *$ \\
\hline Anticoagulation day 2 after surgery ${ }^{c}$ & $\begin{array}{l}\text { Yes(\%) } \\
\text { No(\%) }\end{array}$ & $\begin{array}{l}30(I I .2) \\
47(14.2)\end{array}$ & $\begin{array}{l}239(88.8) \\
284(85.8)\end{array}$ & 0.267 \\
\hline Anticoagulation day 2 after surgery ${ }^{d}$ & $\begin{array}{l}\text { Yes(\%) } \\
\mathrm{No}(\%)\end{array}$ & $\begin{array}{l}25(10.8) \\
52(\mid 4 . I)\end{array}$ & $\begin{array}{l}206(89.2) \\
317(85.9)\end{array}$ & 0.244 \\
\hline
\end{tabular}

Notes: ${ }^{a}$ As-needed subcutaneous injections of nadroparin calcium starting the first day after surgery. ${ }^{\mathrm{b}}$ From the first day after surgery, nadroparin calcium was injected subcutaneously on a regular basis (at least $0.4 \mathrm{~mL}$ daily). ${ }^{\mathrm{C}}$ As-needed injections of nadroparin calcium starting the second day after surgery. ${ }^{\mathrm{d}}$ From the second day after surgery, nadroparin calcium was injected subcutaneously on a regular basis (at least $0.4 \mathrm{~mL}$ daily). *Indicates statistical significance, $P<.05$.

Abbreviation: VTE, venous thromboembolism. 
Table 6 Incidence of VTE After Surgery in Different Disease Categories

\begin{tabular}{|c|c|c|c|}
\hline Study & Total Surgical Patients & Disease Categories & Incidence of Postoperative VTE \\
\hline Cui et $\mathrm{al}^{14}$ & 339 & Pulmonary malignancy & $11.5 \%$ \\
\hline Wang et a $\left.\right|^{15}$ & 249 & Pulmonary malignancy & $14.5 \%$ \\
\hline \multirow[t]{2}{*}{ Tian et al ${ }^{16}$} & 52 & Pulmonary malignancy & $23.1 \%$ \\
\hline & 59 & Pulmonary benign tumor & $10.2 \%$ \\
\hline \multirow[t]{2}{*}{ Song et al ${ }^{17}$} & 147 & Pulmonary malignancy & $15.0 \%$ \\
\hline & 115 & Pulmonary benign disease & $7.0 \%$ \\
\hline \multirow[t]{2}{*}{ Song et $\mathrm{al}^{18}$} & 285 & Pulmonary malignancy & $16.4 \%$ \\
\hline & & Pulmonary benign tumor & $7.5 \%$ \\
\hline Shi et al ${ }^{19}$ & 1133 & Urological malignant tumor & $2.4 \%$ \\
\hline \multirow[t]{2}{*}{ Yoshioka et $\mathrm{al}^{20}$} & 72 & Malignant spine tumor & $4.2 \%$ \\
\hline & & Benign spine surgery & $4.2 \%$ \\
\hline Yang et $\mathrm{al}^{21}$ & 3645 & Colorectal cancer & $0.9 \%$ \\
\hline Kim et $\mathrm{al}^{22}$ & 375 & Gastric Cancer & $2.4 \%$ \\
\hline Dar et $\mathrm{al}^{23}$ & 88 & Abdominal malignancy & $9.0 \%$ \\
\hline Hennessey et $\mathrm{al}^{24}$ & 93,663 & Head and neck cancer & $2.0 \%$ \\
\hline \multirow[t]{2}{*}{ Kimmell et al ${ }^{25}$} & 3098 & Intracranial tumor & $5.0 \%$ \\
\hline & & Benign intracranial disease & $1.9 \%$ \\
\hline
\end{tabular}

Abbreviation: VTE, venous thromboembolism.

Because of the high incidence of lung cancer and VTE, we need to consider whether the preventive anticoagulant therapy should be adjusted accordingly. Currently, preventive anticoagulant therapy after lung cancer surgery is mainly based on clinical consensus and lack of relevant evidence. In addition, postoperative patients have a potential risk of bleeding. Therefore, how to balance the risk of thrombosis and bleeding after surgery needs further study. Previous studies have found that about $7 \%$ of $\mathrm{PE}$ is caused by intermuscular veins, and suggest that patients who have symptomatic MCVT need to be treated with an anticoagulant therapeutic dose lasting at least 15 to 30 days, and it is necessary to prolong the anticoagulation time to prevent the thrombus from extending to the deep vein when related risk factors are present. ${ }^{43}$ Previous study reveals that the majority of postoperative VTE is lower extremity intermuscular venous thromboses, which is consistent with this study (94.8\%), and shows that up to $15 \%$ of the distal VTEs in the first 2 weeks after surgery subsequently progress and affect the proximal vein. ${ }^{42}$ Thrombosis prevention programs include anticoagulant drugs, mechanical measures (intermittent compression therapy and elastic stockings), and early active activities. These programs can effectively reduce the incidence of VTE after lung surgery and our results have confirmed some of them. ${ }^{44}$ Further, LMWH for the preventive treatment of VTE does not significantly increase risk of hemorrhage. ${ }^{45}$ Our findings are in line with the American guidelines which recommend early initiation of systemic thromboprophylaxis for at least 7 to 10 days after tumor surgery. Moreover, their findings suggest an added benefit of mechanical thromboprophylaxis in this population. ${ }^{46}$ Besides, early systemic thromboprophylaxis may be better than regular anticoagulation day 1 after surgery, limb compression therapy in preventing thrombosis.

Hence, prophylactic anticoagulant therapy and limb compression therapy from the first day after surgery, Ddimer examination on day 5 after surgery, and thrombusrelated risk factor analysis can well evaluate the risk of thrombus and help clinicians decide whether to continue anticoagulant therapy.

\section{Study Limitations}

The results of this study were encouraging, but the limitations were not negligible. The study did not have regular follow-up for VTE progression and overall survival of patients postoperatively. Because of the low overall incidence of VTE in the population, comparative studies of postoperative anticoagulation for other types of tumors should be performed in subsequent studies. In addition, the neutrophil-lymphocyte ratio is considered to be a potential biomarker for predicting efficacy and prognosis of anticoagulant therapy in patients with lung cancer, ${ }^{47}$ so relevant research can be conducted in future studies. 


\section{Conclusions}

In conclusion, VTE after pulmonary tumor surgery should cause widespread concern and attention. In addition, Ddimer level and color Doppler ultrasonography of lower extremity veins should be reviewed regularly. After the anticoagulation contraindications are excluded, prophylactic anticoagulant therapy and mechanical thromboprophylaxis should be given as soon as possible according to the patient's condition. When lower extremity intermuscular venous thrombosis occurs, more aggressive treatment should be taken to protect the health of the patient from progression of this condition.

\section{Ethics Approval and Consent to Participate}

This study was approved by the Ethical Review Committee of Tianjin Medical University General Hospital. Venous ultrasound imaging was recommended for all postoperative patients. All biological samples were obtained with patients' written informed consent.

\section{Acknowledgments}

We thank the Peerwith (https://www.peerwith.com/) for English-language editing.

\section{Author Contributions}

All authors made substantial contributions to conception and design, acquisition of data, or analysis and interpretation of data; took part in drafting the article or revising it critically for important intellectual content; gave final approval of the version to be published; and agree to be accountable for all aspects of the work.

\section{Funding}

This work was supported by grants from the National Natural Science Foundation of China (81773207) and the Natural Science Foundation of Tianjin (17YFZCSY00840, 18PTZWHZ00240, 19YFZCSY00040), and Special support program for High Tech Leader \& Team of Tianjin (TJTZJH-GCCCXCYTD-2-6). Funding sources had no role in study design, data collection, and analysis; in the decision to publish; or in the preparation of the manuscript.

\section{Disclosure}

The authors declare that they have no competing interests.

\section{References}

1. Heit JA, O'Fallon WM, Petterson TM, et al. Relative impact of risk factors for deep vein thrombosis and pulmonary embolism: a population-based study. Arch Intern Med. 2002;162(11):1245-1248. doi:10.1097/GME.0000000000001232

2. Heit JA, Silverstein MD, Mohr DN, Petterson TM, O'Fallon WM, Melton LJ 3rd. Risk factors for deep vein thrombosis and pulmonary embolism: a population-based case-control study. Arch Intern Med. 2000;160(6):809-815. doi:10.1001/archinte.160.6.809

3. Zhang Y, Yang Y, Chen W, et al. Prevalence and associations of VTE in patients with newly diagnosed lung cancer. Chest. 2014;146 (3):650-658. doi:10.1378/chest.13-2379

4. Lyman GH, Khorana AA. Cancer, clots and consensus: new understanding of an old problem. J Clin Oncol off J Am Soc Clin Oncol. 2009;27(29):4821-4826. doi:10.1200/JCO.2009.22.3032

5. Vitale C, D'Amato M, Calabro P, Stanziola AA, Mormile M, Molino A. Venous thromboembolism and lung cancer: a review. Multidiscip Respir Med. 2015;10(1):28. doi:10.1186/s40248-015-0021-4

6. White RH, Zhou H, Romano PS. Incidence of symptomatic venous thromboembolism after different elective or urgent surgical procedures. Thromb Haemost. doi:10.1160/TH03-03-0152

7. Ay C, Uenal UK. Epidemiology and risk factors for venous thromboembolism in lung cancer. Curr Opin Oncol. 2016;28(2):145-149. doi:10.1097/CCO.0000000000000262

8. Ma J, Qin SK, Wu YL, et al. Guidelines on prevention and treatment of tumor-associated venous thromboembolism in China (Version 2019). Zhongguo Zhong Liu Lin Chuang. 2019;46(13):653-660. doi:10.3969/j.issn.1000-8179.2019.13.765

9. Lyman GH, Bohlke K, Khorana AA, et al. Venous thromboembolism prophylaxis and treatment in patients with cancer: american society of clinical oncology clinical practice guideline update 2014. J Clin Oncol. 2015;33(6):654-656. doi:10.1200/JCO.2014.59.7351

10. Kourelis TV, Wysokinska EM, Wang Y, Yang P, Mansfield AS, Tafur AJ. Early venous thromboembolic events are associated with worse prognosis in patients with lung cancer. Lung Cancer. 2014;86 (3):358-362. doi:10.1016/j.lungcan.2014.10.003

11. Trujillo-Santos J, Casas JM, Casado I, et al. Erratum to "Thirty-day mortality rate in women with cancer venous thromboembolism. Findings from the RIETE registry" [Thrombosis research (2011) S1-S4]. Thromb Res. 2011;128(2):e1. doi:10.1016/j.thromres.2011. 02.021

12. Zamorano JL, Lancellotti P, Rodriguez Munoz D, et al. 2016 ESC Position Paper on cancer treatments and cardiovascular toxicity developed under the auspices of the ESC Committee for Practice Guidelines: the Task Force for cancer treatments and cardiovascular toxicity of the European Society of Cardiology (ESC). Eur J Heart Fail. 2017;19(1):9-42. doi:10.5603/KP.2016.0156

13. Paneesha S, McManus A, Arya R, et al. Frequency, demographics and risk (according to tumour type or site) of cancer-associated thrombosis among patients seen at outpatient DVT clinics. Thromb Haemost. 2010;103(2):338-343. doi:10.1160/TH09-06-0397

14. Cui S, Li H, Tian B, Song C, Hu B. [Risk factors associated with venous thromboembolism after lung cancer surgery: a single-center study]. Zhongguo Fei Ai Za Zhi. 2018;21(10):753-760. Chinese. doi:10.3779/j.issn.1009-3419.2018.10.04

15. Wang X, Song S, Ni R, Lu M, Mao Y. Effectiveness of intraoperative administration of intermittent pneumatic compression in preventing deep vein thrombosis in lung cancer patients undergoing videoassisted thoracoscopic surgery lobectomy. J Thorac Dis. 2019;11 (7):2832-2838. doi:10.21037/jtd.2019.07.07

16. Tian B, Song C, Li H, et al. The significance of perioperative coagulation and fibrinolysis related parameters after lung surgery for predicting venous thromboembolism: a prospective, single center study. J Thorac Dis. 2018;10(4):2223-2230. doi:10.21037/jtd.2018. 03.174 
17. Song C, Shargall Y, Li H, et al. Prevalence of venous thromboembolism after lung surgery in China: a single-centre, prospective cohort study involving patients undergoing lung resections without perioperative venous thromboembolism prophylaxis? Eur J Cardiothorac Surg. 2019;55(3):455-460. doi:10.1093/ejcts/ezy323

18. Song CF, Li H, Tian B, et al. [Incidence of postoperative venous thromboembolism after thoracic surgery and its characteristic: a single center, prospective cohort study]. Zhonghua Wai Ke Za Zhi. 2018;56(4):284-288. Chinese. doi:10.3760/cma.j.issn.05295815.2018.E008

19. Shi A, Huang J, Wang X, et al. Postoperative D-dimer predicts venous thromboembolism in patients undergoing urologic tumor surgery. Urol Oncol. 2018;36(6):307.e15-307.e21. doi:10.1016/j. urolonc.2018.03.003

20. Yoshioka K, Kitajima I, Kabata T, et al. Venous thromboembolism after spine surgery: changes of the fibrin monomer complex and Ddimer level during the perioperative period. J Neurosurg Spine. 2010;13(5):594-599. doi:10.1016/j.urolonc.2018.03.003

21. Yang SS, Yu CS, Yoon YS, Yoon SN, Lim SB, Kim JC. Symptomatic venous thromboembolism in Asian colorectal cancer surgery patients. World J Surg. 2011;35(4):881-887. doi:10.1007/s00268-011-0957-2

22. Kim JW, Chun EJ, Choi SI, et al. A prospective study on the incidence of postoperative venous thromboembolism in Korean gastric cancer patients: an inquiry into the application of Western guidelines to Asian cancer patients. PLoS One. 2013;8(4):e61968. doi:10.1371/journal.pone.0061968

23. Dar TI, Wani KA, Ashraf M, et al. Low molecular weight heparin in prophylaxis of deep vein thrombosis in Asian general surgical patients: a Kashmir experience. Indian J Crit Care Med. 2012;16 (2):71-74. doi:10.4103/0972-5229.99107

24. Hennessey P, Semenov YR, Gourin CG. The effect of deep venous thrombosis on short-term outcomes and cost of care after head and neck cancer surgery. Laryngoscope. 2012;122(10):2199-2204. doi:10.1002/lary.23459

25. Kimmell KT, Walter KA. Risk factors for venous thromboembolism in patients undergoing craniotomy for neoplastic disease. $J$ Neurooncol. 2014;120(3):567-573. doi:10.1007/s11060-014-1587-y

26. Lopez-Gomez M, Gomez-Raposo C, Lobo Samper F. Frequency, risk factors, and trends for venous thromboembolism among hospitalized cancer patients. Cancer. 2008;113(1):223-224; author reply 224. doi:10.1002/cncr.23524

27. Starling N, Rao S, Cunningham D, et al. Thromboembolism in patients with advanced gastroesophageal cancer treated with anthracycline, platinum, and fluoropyrimidine combination chemotherapy: a report from the UK national cancer research institute upper gastrointestinal clinical studies group. J Clin Oncol. 2009;27(23):37863793. doi:10.1200/JCO.2008.19.4274

28. de Meis E, Pinheiro VR, Zamboni MM, et al. Clotting, immune system, and venous thrombosis in lung adenocarcinoma patients: a prospective study. Cancer Invest. 2009;27(10):989-997. doi:10.3109/ 07357900903124464

29. Kilickap S, Abali H, Celik I. Bevacizumab, bleeding, thrombosis, and warfarin. J Clin Oncol. 2003;21(18):3542; author reply 3543. doi:10.1200/JCO.2003.99.046

30. Kadlec B, Skrickova J, Merta Z, Dusek L, Jarkovsky J. The incidence and predictors of thromboembolic events in patients with lung cancer. ScientificWorldJournal. 2014;2014:125706. doi:10.1155/2014/125 706

31. Lee YG, Kim I, Lee E, et al. Risk factors and prognostic impact of venous thromboembolism in Asian patients with non-small cell lung cancer. Thromb Haemost. 2014;111(6):1112-1120. doi:10.1160/TH1 3-11-0956
32. Steuer CE, Behera M, Kim S, et al. Predictors and outcomes of venous thromboembolism in hospitalized lung cancer patients: a nationwide inpatient sample database analysis. Lung Cancer. 2015;88(1):80-84. doi:10.1016/j.lungcan.2015.01.022

33. Khaldi A, Helo N, Schneck MJ, Origitano TC. Venous thromboembolism: deep venous thrombosis and pulmonary embolism in a neurosurgical population. J Neurosurg. 2011;114(1):40-46. doi:10.3171/ 2010.8.JNS10332

34. Corrales-Rodriguez L, Blais N. Lung cancer associated venous thromboembolic disease: a comprehensive review. Lung Cancer. 2012;75(1):1-8. doi:10.1016/j.lungcan.2011.07.004

35. Yang Y, Zhou Z, Niu XM, et al. Clinical analysis of postoperative venous thromboembolism risk factors in lung cancer patients. J Surg Oncol. 2012;106(6):736-741. doi:10.1002/jso.23190

36. Christensen TD, Vad H, Pedersen S, et al. Venous thromboembolism in patients undergoing operations for lung cancer: a systematic review. Ann Thorac Surg. 2014;97(2):394-400. doi:10.1016/j. athoracsur.2013.10.074

37. Merkow RP, Bilimoria KY, McCarter MD, Barnett CC, Caprini JA, Bentrem DJ. Post-discharge venous thromboembolism in surgical oncology: extending the case for extended prophylaxis. J Am Coll Surg. 2010;211(3):3. doi:10.1016/j.jamcollsurg.2010.06.252

38. Donnellan E, Khorana AA. Cancer and venous thromboembolic disease: a review. The Oncologist. 2017;22(2):199-207. doi:10.1634/ theoncologist.2016-0214

39. Khorana AA, Francis CW, Culakova E, Kuderer NM, Lyman GH. Frequency, risk factors, and trends for venous thromboembolism among hospitalized cancer patients. Cancer. 2007;110(10):23392346. doi:10.1002/cncr.23062

40. Yoshiiwa T, Miyazaki M, Takita C, Itonaga I, Tsumura H. Analysis of measured D-dimer levels for detection of deep venous thrombosis and pulmonary embolism after spinal surgery. J Spinal Disord Tech. 2011;24(4):E35-39. doi:10.1097/BSD.0b013e3181f60603

41. Karsy M, Azab MA, Harper J, et al. Evaluation of a D-dimer protocol for detection of venous thromboembolism. World Neurosurg. 2020;133:e774-774e783. doi:10.1016/j.wneu.2019.09.160

42. Prell J, Rachinger J, Smaczny R, et al. D-dimer plasma level: a reliable marker for venous thromboembolism after elective craniotomy. J Neurosurg. 2013;119(5):1340-1346. doi:10.3171/2013.5.JNS 13151

43. Gillet JL, Perrin MR, Allaert FA. Short-term and mid-term outcome of isolated symptomatic muscular calf vein thrombosis. J Vasc Surg. 2007;46(3):513-519. doi:10.1016/j.jvs.2007.04.040.

44. Gomez-Hernandez MT, Rodriguez-Perez M, Novoa-Valentin N, Jimenez-Lopez M, Aranda-Alcaide JL, Varela-Simo G. Prevalence of venous thromboembolism in elective thoracic surgery. Arch Bronconeumol. 2013;49(7):297-302. doi:10.1016/j.arbres.2013.01. 011

45. Fuentes HE, Oramas DM, Paz LH, Casanegra AI, Mansfield AS, Tafur AJ. Meta-analysis on anticoagulation and prevention of thrombosis and mortality among patients with lung cancer. Thromb Res. 2017;154:28-34. doi:10.1016/j.thromres.2017.03.024

46. Lyman GH, Kuderer NM. Prevention and treatment of venous thromboembolism among patients with cancer: the American Society of Clinical Oncology Guidelines. Thromb Res. 2010;125(Suppl 2): S120-127. doi:10.1016/S0049-3848(10)70029-3

47. Go SI, Lee A, Lee US, et al. Clinical significance of the neutrophillymphocyte ratio in venous thromboembolism patients with lung cancer. Lung Cancer. 2014;84(1):79-85. doi:10.1016/j.lungcan.20 14.01.014 


\section{Publish your work in this journal}

Cancer Management and Research is an international, peer-reviewed open access journal focusing on cancer research and the optimal use of preventative and integrated treatment interventions to achieve improved outcomes, enhanced survival and quality of life for the cancer patient.
The manuscript management system is completely online and includes a very quick and fair peer-review system, which is all easy to use. Visit http://www.dovepress.com/testimonials.php to read real quotes from published authors.

Submit your manuscript here: https://www.dovepress.com/cancer-management-and-research-journal 